\title{
Resource partitioning between incubating and chick-rearing brown boobies and red-tailed tropicbirds on Christmas Island
}

\author{
Joan Navarro ${ }^{1 *}$, Rocio Moreno ${ }^{2,3}$, Lena Braun ${ }^{4}$, Carola Sanpera ${ }^{3}$ and Janos C Hennicke ${ }^{4,5}$
}

\begin{abstract}
Background: In oligotrophic tropical marine environments, the main mechanism explaining the coexistence of sympatric seabirds is segregation by habitat or segregation by prey within the same habitat. Both types of segregation can play a role during the breeding season due to different constraints associated with different phases of the breeding cycle. By using stable isotope analyses, we investigated intra- and interspecific foraging segregation in two tropical seabird species, the red-tailed tropicbird Phaeton rubricauda and the brown booby Sula leucogaster, breeding sympatrically on Christmas Island, Indian Ocean. We compared isotopic values of $\delta^{13} \mathrm{C}$ and $\delta^{15} \mathrm{~N}$ in blood from incubating and chick-rearing adults of both species.

Results: The results showed small but significantly interspecific and intraspecific differences in $\delta^{13} \mathrm{C}$ and $\delta^{15} \mathrm{~N}$ values. Differences in $\delta^{13} \mathrm{C}$ values suggest spatial segregation in the main foraging grounds between the two species during the breeding season as well as between incubating and chick-rearing brown boobies. In contrast, red-tailed tropicbirds probably exploited similar foraging habitats during both breeding stages. $\delta^{15} \mathrm{~N}$ values did not indicate diet-related differences, neither within nor between species, suggesting a highly opportunistic feeding behavior to cope with the limited prey available in the oligotrophic marine environment.
\end{abstract}

Conclusions: Competition for prey in breeding red-tailed tropicbirds and brown boobies seems to be reduced by spatial segregation enabling both species to successfully reproduce in sympatry in an oligotrophic tropical marine environment.

Keywords: Feeding segregation; Stable isotope analysis; Tropical ecosystems; Seabirds

\section{Background}

Tropical marine ecosystems are characterized by low productivity in comparison with non-tropical systems (Miller 2003). These oligotrophic ecosystems can only sustain relatively low densities of top marine predators such as seabirds, which mainly feed upon a few groups of prey species, generally flying fish (Exocoetidae) and squids (Ommastrephidae) (Ashmole and Ashmole 1967; Longhurst and Pauly 1987). Consequently, tropical seabirds must adapt their foraging behavior to mitigate potential competition for the limited food resources within their foraging areas (Spear et al. 2007; Cherel et al. 2008). The main mechanisms currently explaining the coexistence of

\footnotetext{
*Correspondence: joan@icm.csic.es

${ }^{1}$ Institut de Ciències del Mar (ICM-CSIC), P. Marítim de la Barceloneta 37-49, Barcelona 08003, Spain

Full list of author information is available at the end of the article
}

sympatric tropical seabirds are segregation by feeding habitat or segregation by prey selection within the same habitat (Diamond 1983; Harrison et al. 1983; Cherel et al. 2008; Young et al. 2010). Both types of segregation can play a role over the course of the breeding season due to different constraints associated with different phases of the breeding cycle, e.g., incubation vs. chick rearing (Ashmole and Ashmole 1967; Cherel et al. 2008). So far, most studies on resource partitioning have been conducted in marine habitats of polar and temperate waters (Phillips et al. 2005; Forero et al. 2004; Masello et al. 2010; Navarro et al. 2013) and little is known about how sympatric seabirds of tropical waters reduce inter- and intraspecific competition for prey resources or whether the types of segregation shift over the course of the breeding season (Catry et al. 2009; Cherel et al. 2008). 
Recent analytical developments have provided useful tools to study feeding and foraging ecology in marine predators. In particular, the analysis of stable isotopes has been shown to be an effective technique to investigate the trophic structure of marine food webs and resource allocation of sympatric seabirds (Cherel et al. 2008, Kojadinovic et al. 2008; Moreno et al. 2013). The principle underlying this approach is that stable isotope ratios of nitrogen $\left(\delta^{15} \mathrm{~N}\right)$ and carbon $\left(\delta^{13} \mathrm{C}\right)$ in predators reflect those of their prey species in a predictable manner (Karnovsky et al. 2012). $\delta^{15} \mathrm{~N}$ values show a stepwise enrichment between $3 \%$ to $5 \%$ with each trophic level and are reliable indicators of the consumer's trophic position (Inger and Bearhop 2008). $\delta^{13} \mathrm{C}$ values indicate consumer foraging areas discriminating between inshore/benthic and offshore/pelagic feeding (Forero and Hobson 2003; Inger and Bearhop 2008).

In the present study, we aimed to investigate the main mechanisms that may explain the coexistence of two abundant sympatric tropical seabird species, the red-tailed tropicbird Phaethon rubricauda and the brown booby Sula leucogaster on Christmas Island (Indian Ocean; Figure 1). On this island, these species breed at the same time providing the ideal setting to investigate potential segregation over the course of the breeding season since, at a given time, animals in different breeding stages forage under the same environmental conditions. Thus, our objectives were to determine interspecific as well as intraspecific (between sexes) segregation in trophic niche and foraging habitat during incubation and chick rearing by using stable isotope analyses of $\delta^{15} \mathrm{~N}$ and $\delta^{13} \mathrm{C}$.

\section{Methods}

\section{Fieldwork procedures and study species}

The study was conducted on Christmas Island (Figure 1, $\left.105^{\circ} 40^{\prime} \mathrm{E} ; 10^{\circ} 30^{\prime} \mathrm{S}\right)$, a small $\left(135 \mathrm{~km}^{2}\right)$ tropical Australian island in the north-eastern Indian Ocean, $360 \mathrm{~km}$ south of Java, Indonesia. Red-tailed tropicbirds and brown boobies breed in sympatry on Christmas Island with seven other seabird species (Nelson 1972; Stokes 1988). Approximately 1,400 pairs of red-tailed tropicbirds and 6,000 pairs of brown boobies nest on the coastal terraces and limestone cliffs of this island (Stokes 1988). Egg-laying of both species occurs year-round peaking from June to October (Stokes 1988).

During the breeding period of 2007 (September to October), we collected $0.5 \mathrm{ml}$ of blood from incubating and chick-rearing adults of both species. In red-tailed tropicbirds, we sampled 19 incubating birds (10 males and 9 females) and 21 chick-rearing adults (10 males and 11 females). In brown boobies, we sampled 19 incubating birds (10 males and 9 females) and 73 chick-rearing adults (37 males and 36 females). All individuals were sampled only once, either during incubation or during chick rearing. Blood was taken from the brachial vein using a $0.5-\mathrm{ml}$ insulin syringe and preserved in $70 \%$ ethanol. Blood extraction is a method commonly used in bird studies that apparently have not negative effect

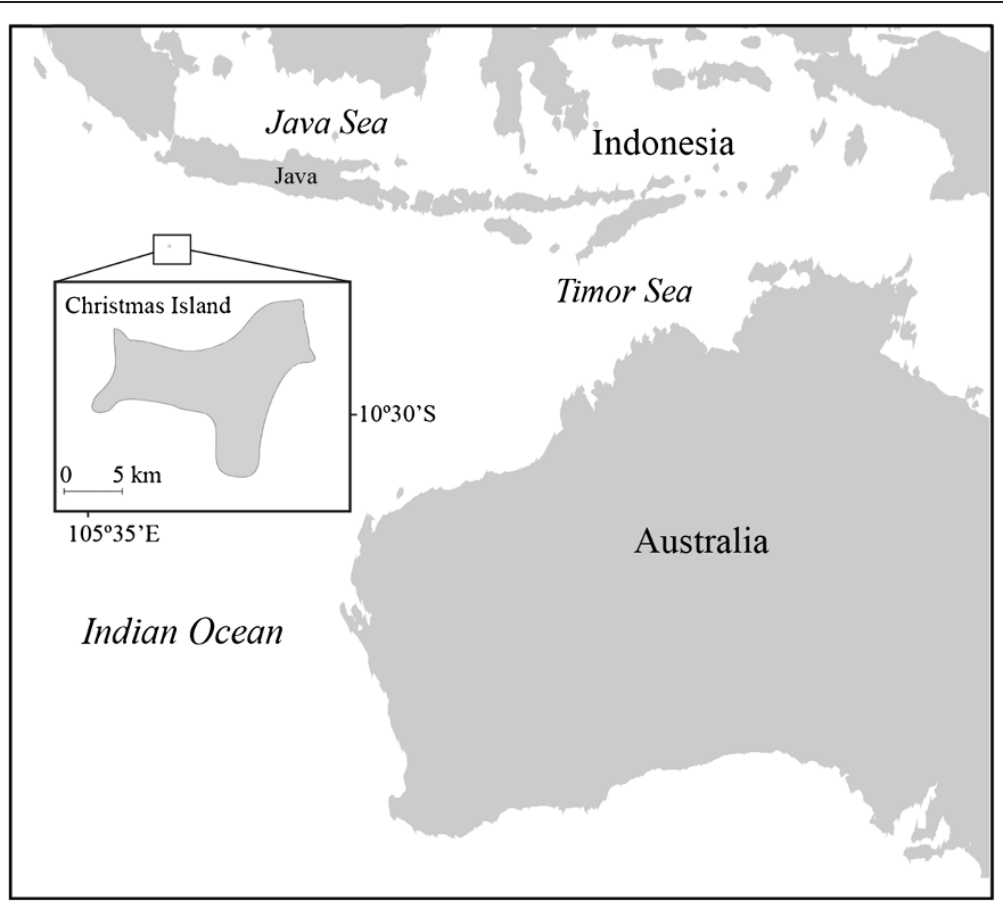

Figure 1 Geographic location of Christmas Island, Indian Ocean. 
on foraging behavior and survival (Angelier et al. 2011). All birds were caught at their nests using a 1-m-long noose pole and were individually color-marked on the head or breast with a green or blue sheep crayon to avoid sampling the same individual twice. The sex of brown boobies was determined by their sexual dimorphism (Nelson 1978), whereas red-tailed tropicbirds were sexed using molecular W chromosome-linked markers (Ellegren 1996).

\section{Stable isotope analyses}

Prior to isotopic analyses, blood samples were dried at $60^{\circ} \mathrm{C}$ for $24 \mathrm{~h}$ to remove ethanol. Once homogenized, an aliquot of $0.4 \mathrm{mg}$ of each blood sample was weighed to the nearest microgram $(\mu \mathrm{g})$ and placed in a $\mathrm{Sn}$ capsule. Samples were oxidized with $\mathrm{CuO}$ and $\mathrm{CO}_{3} \mathrm{O}_{4} / \mathrm{Ag}$ at about $900^{\circ} \mathrm{C}$ in a Flash EA 1112 Elemental Analyzer coupled to a pyrolyzer TC-EA and a breath bench through a Conflo III Finnigan MAT interface. $\mathrm{NO}_{2}$ was reduced with $\mathrm{Cu}$ at $680^{\circ} \mathrm{C}$. The combustion products $\mathrm{N}_{2}$ and $\mathrm{CO}_{2}$ were flowed through a Delta $\mathrm{C}$ Finnigan MAT mass spectrometer through an $\mathrm{MgClO}_{4}$ drying column. The isotope-ratio mass spectrometry facility at the Serveis Científico-Tècnics of the University of Barcelona (Spain) applies international standards, generally run for each of the 12 samples; IAEA $\mathrm{CH}_{7}$ (87\% of C), IAEA $\mathrm{CH}_{6}$ (42\% of C), and USGS 24 (100\% of $\mathrm{C}$ ) for ${ }^{13} \mathrm{C}$ and IAEA $\mathrm{N}_{1}$ and IAEA $\mathrm{N}_{2}$ (with $21 \%$ of $\mathrm{N}$ ) and IAEA $\mathrm{NO}_{3}(13.8 \%$ of $\mathrm{N})$ for ${ }^{15} \mathrm{~N}$. Replicate assays of standards indicated measurement errors of \pm 0.1 and \pm 0.2 for carbon and nitrogen, respectively. Based on the low $\mathrm{C} / \mathrm{N}$ ratio (less than 0.4 for all individuals; Table 1 ) we did not remove the lipids from the blood samples.

Table 1 Mean and SD of $\delta^{15} \mathrm{~N}$ and $\delta^{13} \mathrm{C}$ values and range (minimum and maximum) $\mathrm{C} / \mathrm{N}$ ratio in blood

\begin{tabular}{|c|c|c|c|c|}
\hline & Sample, $n$ & $\delta^{15} \mathrm{~N}(\% \circ)$ & $\delta^{13} \mathrm{C}(\% \circ)$ & $\mathrm{C} / \mathrm{N}$ \\
\hline & & Mean (SD) & Mean (SD) & Range \\
\hline \multicolumn{5}{|l|}{ BRBO } \\
\hline Incubation & & $12.17(0.11)$ & $-16.71(0.14)$ & 0.29 to 0.32 \\
\hline Males & 10 & $12.12(0.07)$ & $-16.72(0.11)$ & 0.31 to 0.32 \\
\hline Females & 9 & $12.23(0.12)$ & $-16.68(0.18)$ & 0.29 to 0.32 \\
\hline Chick rearing & & $12.31(0.23)$ & $-16.88(0.22)$ & 0.30 to 0.33 \\
\hline Males & 27 & $12.25(0.18)$ & $-16.88(0.24)$ & 0.31 to 0.32 \\
\hline Females & 27 & $12.35(0.28)$ & $-16.84(0.18)$ & 0.31 to 0.34 \\
\hline \multicolumn{5}{|l|}{ RTTB } \\
\hline Incubation & & $12.63(0.23)$ & $-16.96(0.17)$ & 0.30 to 0.32 \\
\hline Males & 10 & $12.62(0.31)$ & $-16.99(0.18)$ & 0.30 to 0.32 \\
\hline Females & 9 & $12.63(0.13)$ & $-16.94(0.16)$ & 0.31 to 0.32 \\
\hline Chick rearing & & $12.68(0.27)$ & $-16.91(0.19)$ & 0.29 to 0.32 \\
\hline Males & 14 & $12.74(0.27)$ & $-17.09(0.38)$ & 0.31 to 0.32 \\
\hline Females & 13 & $12.62(0.41)$ & $-16.93(0.27)$ & 0.29 to 0.31 \\
\hline
\end{tabular}

These are from male and female brown boobies (BRBO) and red-tailed tropicbirds (RTTB) during the incubation and chick rearing period on Christmas Island, Indian Ocean. The mean values for each species during both breeding stages are indicated in italics.

\section{Statistical procedures}

Statistical analyses were conducted using IBM SPSS 21.0 (IBM SPSS). Prior to statistical tests, data were checked for normality and heteroscedasticity. ANOVA tests incorporating species, breeding stage (incubation and chick rearing) and sex were used to test for interspecific and intraspecific differences in $\delta^{15} \mathrm{~N}$ and $\delta^{13} \mathrm{C}$ values. As neither sex nor the interaction of sex and breeding stage had significant effects on isotopic values, data from both sexes were pooled. Since stable isotope values differed between species, Student's $t$ tests were used to compare the isotopic values for each species separately to determine differences between breeding stages. All tests were two-tailed and the threshold for significance was $p<0.05$.

\section{Results}

Isotopic comparison between species

At interspecific level, we found significant isotopic differences between red-tailed tropicbirds and brown boobies (Figure 2; Table 1; $\delta^{15} \mathrm{~N}: \mathrm{F}_{1,116}=805.11, p<0.0001 ; \delta^{13} \mathrm{C}$ : $\mathrm{F}_{1,116}=10.01, \quad p=0.001 ;$ absolute differences; $\delta^{15} \mathrm{~N}=$ $0.41 \%$ o, $\delta^{13} \mathrm{C}=0.25 \%$ o). In particular, during the incubation period red-tailed tropicbirds showed higher $\delta^{15} \mathrm{~N}$ values and lower $\delta^{13} \mathrm{C}$ values than brown boobies (Figure 2; $\delta^{15} \mathrm{~N}: t=-7.81, d f=35, p<0.001 ; \delta^{13} \mathrm{C}: t=4.97, d f=35$, $p<0.0001$; absolute differences; $\delta^{15} \mathrm{~N}=0.46 \%$, $\delta^{13} \mathrm{C}=$ $0.48 \%$ ). During the chick-rearing period, red-tailed tropicbird showed significantly higher $\delta^{15} \mathrm{~N}$ values and similar $\delta^{13} \mathrm{C}$ values than brown boobies (Figure $2 ; \delta^{15} \mathrm{~N}: t=-6.05$, $d f=91, p<0.001 ; \delta^{13} \mathrm{C}: t=-2.27, d f=91, p=0.78$; absolute differences; $\delta^{15} \mathrm{~N}=0.37 \%$, $\delta^{13} \mathrm{C}=0.03 \%$ o).

\section{Isotopic comparison between incubation and chick- rearing periods}

At intraspecific level, we found that incubating brown boobies showed lower $\delta^{15} \mathrm{~N}$ and higher $\delta^{13} \mathrm{C}$ values than chickrearing brown boobies (Figure 2; Table $1 ; \delta^{15} \mathrm{~N}: t=2.91$, $d f=90, p=0.004 ; \delta^{13} \mathrm{C}: t=-3.23, d f=90, p=0.002$; absolute differences; $\quad \delta^{15} \mathrm{~N}=0.14 \%, \quad \delta^{13} \mathrm{C}=0.17 \%$ ). In contrast, red-tailed tropicbirds did not differ in $\delta^{15} \mathrm{~N}$ and $\delta^{13} \mathrm{C}$ values between incubating and chick-rearing adults (Figure 2; Table 1; $\delta^{14} \mathrm{~N}: t=0.66, d f=38, p=0.51$; $\left.\delta^{13} \mathrm{C}: t=1.18, d f=38, p=0.24\right)$.

\section{Discussion and conclusions}

The present study revealed both interspecific and intraspecific differences in $\delta^{13} \mathrm{C}$ and $\delta^{15} \mathrm{~N}$ values. Even though absolute differences in the $\delta^{13} \mathrm{C}$ values between species as 


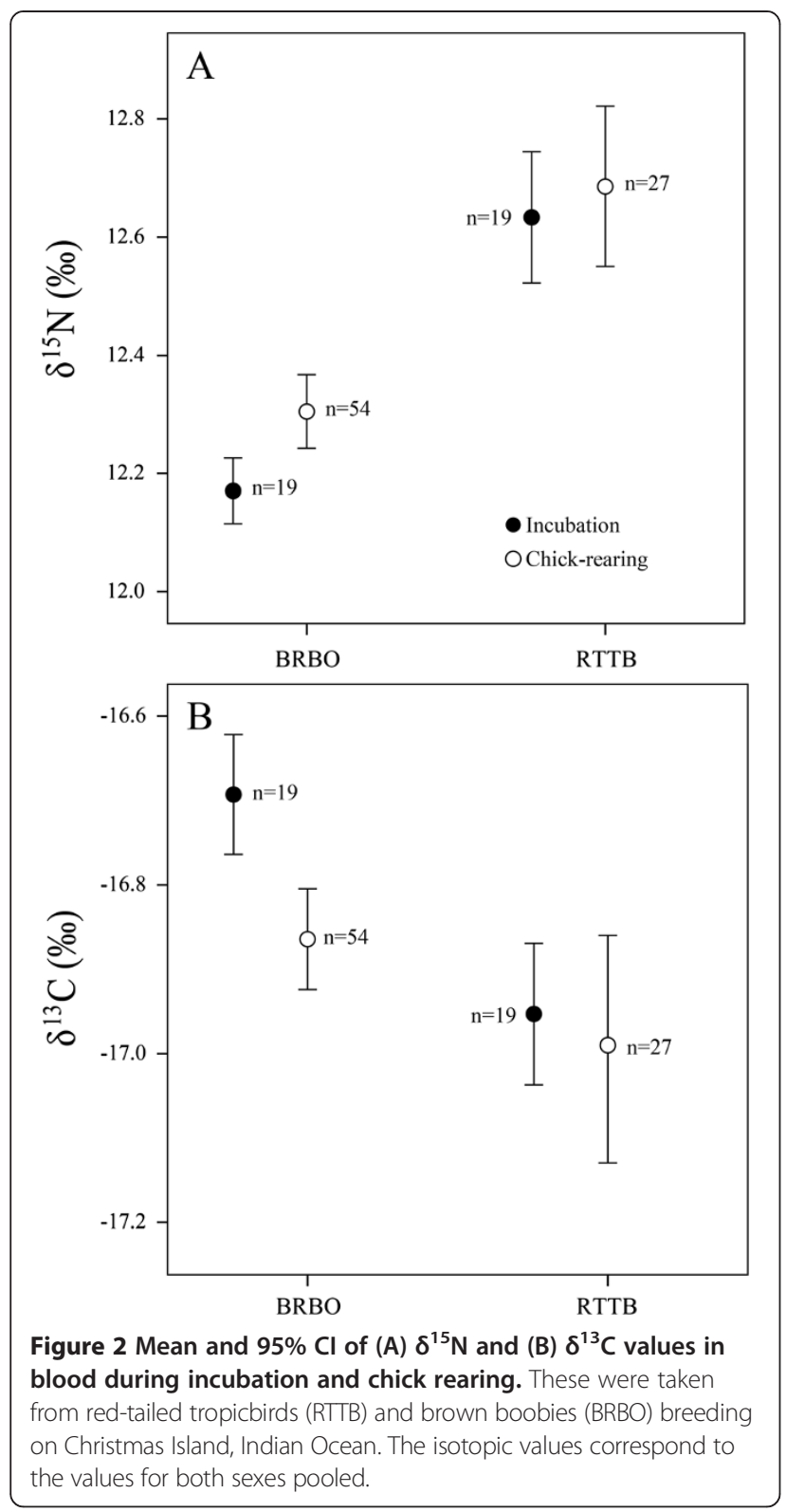

well as between incubating and chick-rearing brown boobies were small $(<0.3 \%)$, the isotopic results are supported by the available information about the foraging behavior of the two species and the energetic requirements during breeding. Given the evidence of a decreasing inshoreoffshore $\delta^{13} \mathrm{C}$ gradient described for marine ecosystems (Hobson et al. 2002; Forero and Hobson 2003), the differences in $\delta^{13} \mathrm{C}$ values between the two study species and between incubating and chick-rearing brown boobies suggest the utilization of different foraging areas. In particular, the lower $\delta^{13} \mathrm{C}$ values of red-tailed tropicbirds suggest that they forage further offshore during both breeding stages than incubating brown boobies (higher $\delta^{13} \mathrm{C}$ values), which seem to use more inshore/coastal foraging areas. During incubation, brown boobies usually make relatively short foraging trips of only several hours and thus feed in areas close to their breeding sites (Nelson 1978; Dunlop et al. 2001; Lewis et al. 2004). In contrast, red-tailed tropicbirds perform long foraging trips, up to several days, to feed in waters far from their breeding colonies (Dunlop et al. 2001; Le Corre et al. 2003; Sommerfeld and Hennicke 2010). The intraspecific differences in $\delta^{13} \mathrm{C}$ values found between incubating and chick-rearing brown boobies suggest a shift in foraging habitat towards more distant foraging areas during chick rearing. Potentially, this is a consequence of different energetic demands during the two breeding stages. Brown boobies reproduce year-round (Nelson 1978; Stokes 1988) and hence incubating and chick-rearing adults are in demand of food at the same time. Since chick-rearing adults must find food not only for themselves but also for their chicks, i.e., they have higher energetic demands, they should try to reduce direct competition for food with conspecifics, e.g., by foraging in more distant waters (Ashmole and Ashmole 1967; Ashmole 1968; Birt et al. 1987). Alternatively, they could switch foraging areas to obtain prey of higher energetic value as it has been found in other seabirds (Ricklefs 1983; Shaffer et al. 2003; Navarro et al. 2007).

The fact that the absolute differences in $\delta^{13} \mathrm{C}$ values between the species and between incubating and chickrearing boobies were relatively small may be explained by the fact that, despite spatial segregation in foraging habitat, there is still overlap in foraging areas as the opportunistically foraging birds (see below) will also take prey close to the island on their way to and from their more distant foraging areas. Moreover, the actual differences in distance between the different foraging areas might be small relative to the mobility of the prey and the relatively weak $\delta^{13} \mathrm{C}$ gradient in tropical waters (Catry et al. 2008, 2009; Cherel et al. 2008). Thus, while the isotopic methods used in the present study suggest spatial segregation, further investigations using tracking devices would be helpful to quantify the habitat segregation/overlap between the species and breeding stages.

In the case of red-tailed tropicbirds, no significant differences in $\delta^{13} \mathrm{C}$ values were found between incubating and chick-rearing adults, indicating an overlap in the habitat used during both breeding periods. This can be attributed to the fact that in this species competition between incubating and chick-rearing congeners is always relatively low due to their off-shore foraging behavior (see above) and their small population size on Christmas Island (1,400 breeding pairs; Stokes 1988). Thus, shifts in foraging areas between breeding stages seems unlikely to result in substantially less competition and hence foraging even further away from Christmas Island seems to be unnecessary for chick-rearing redtailed tropicbirds. 
Differences in $\delta^{15} \mathrm{~N}$ values generally reflect the exploitation of resources of different trophic levels by the consumers (e.g., Hobson et al. 1994; Inger and Bearhop 2008; Moreno et al. 2011). We found significant differences in $\delta^{15} \mathrm{~N}$ values between the two species and between incubating and chick-rearing brown boobies. However, differences in $\delta^{15} \mathrm{~N}$ between two consumers that segregate their diet, i.e. exploit prey of different trophic levels, are usually associated with $\delta^{15} \mathrm{~N}$ values differing by $3 \%$ to $4 \%$ (Post 2002). In our case, the differences were about one magnitude lower and generally less than $0.4 \%$. Thus, while statistically significant, the differences in $\delta^{15} \mathrm{~N}$ values are not biologically relevant and suggest that the two species, as well as incubating and chick-rearing brown boobies, exploit similar resources. The observed differences in the $\delta^{15} \mathrm{~N}$ values can most likely be attributed to the influence of protein catabolism related to differences in foraging effort (Hobson et al. 1993; Cherel et al. 2005; Navarro et al. 2007), i.e., higher effort of off-shore foraging red-tailed tropicbirds vs. in-shore foraging brown boobies and of chick-provisioning vs. incubating brown boobies.

Thus, given the limited and homogenously distributed prey availability in their tropical marine foraging habitat, brown boobies and red-tailed tropicbirds seem to have a strong overlap in their diet during the breeding season and opportunistically exploit whatever prey is available, most likely flying fish and squid, the main and most abundant prey of tropical seabirds (e.g., Ashmole and Ashmole 1967; Ballance and Pitman 1999; Catry et al. 2009). The resulting competition for prey is likely to be reduced by spatial segregation in foraging habitat, facilitating successful reproduction in sympatry in a tropical marine environment with unfavorable prey availability. Additional studies using tracking devices and examining isotopic references of the trophic resources of the species would help to further elucidate ecological mechanisms explaining the coexistence of red-tailed tropicbirds and brown boobies on Christmas Island.

Competing interests

The authors declare that they have no competing interests.

\section{Authors' contributions}

$J \mathrm{~N}$ and $\mathrm{JH}$ designed the study. $\mathrm{JN}$, JH, and $\mathrm{LB}$ carried out fieldwork procedures; JN, JH and RM analyzed the data; JN, JH, RM, and CS wrote the manuscript. All authors read and approved the final manuscript.

\section{Acknowledgements}

The study was conducted within the framework of the Christmas Island Seabird Project (www.seabirdproject.cx), which was supported by the University of Hamburg Research Fund, Christmas Island Tourist Association, Island Explorer Holidays, Cl Territory Week Committee, and CI Island Care. We thank Xavier Ruiz for their scientific support to this project. Funding for the analysis was provided by project SGR 2009963 (Generalitat de Catalunya). Fieldwork was carried out under permission of Parks Australia North Christmas Island and Darwin and was approved by the Animal Ethics Committee of Charles Darwin University, Darwin, Australia. We thank Parks Australia North Christmas Island for their support in all aspects of the study and to M. van der Stap for her help in the field.

\section{Author details}

${ }^{1}$ Institut de Ciències del Mar (ICM-CSIC), P. Marítim de la Barceloneta 37-49, Barcelona 08003, Spain. ${ }^{2}$ British Antarctic Survey, Natural Environment Research Council, High Cross, Madingley Road, Cambridge CB3 OET, UK.

${ }^{3}$ Departament de Biologia Animal (Vertebrats), Facultat de Biologia, Universitat de Barcelona, Av. Diagonal 645, Barcelona 08028, Spain.

${ }^{4}$ Department of Ecology and conservation, Biocentre Grindel, University of Hamburg, Martin-Luther-King-Platz 37, Hamburg 20146, Germany.

${ }^{5}$ Centre d'Études Biologiques de Chizé, UPR 1934 du CNRS,

Villiers-en-Bois 79360, France.

Received: 20 February 2014 Accepted: 19 May 2014

Published online: 04 June 2014

\section{References}

Angelier F, Weimerskirch H, Chastel O (2011) Capture and blood sampling do not affect foraging behaviour, breeding success and return rate of a large seabird: the black-browed albatross. Polar Biol 34:353-361

Ashmole NP (1968) Body size, prey size, and ecological segregation in five sympatric tropical terns (Aves: Laridae). Syst Biol 17:292-304

Ashmole NP, Ashmole MJ (1967) Comparative feeding ecology of sea birds of a tropical oceanic island, vol 24. Peabody Museum of Natural History, Yale University, USA

Ballance LT, Pitman RL (1999) Foraging ecology of tropical seabirds. Proceedings of the 22nd International Ornithological Congress, Durban, pp 2057-2071

Birt VL, Birt TP, Goulet D, Cairns DK, Montevecchi WA (1987) Ashmole's halo: direct evidence for prey depletion by a seabird. Mar Ecol Prog Ser 40:205-208

Catry T, Ramos JA, Le Corre M, Kojadinovic J, Bustamante P (2008) The role of stable isotopes and mercury concentrations to describe seabird foraging ecology in tropical environments. Mar Biol 155:637-647

Catry T, Ramos JA, Jaquemet S, Faulquier L, Berloncourt M, Hauselmann A, Pinet P, Le Corre M (2009) Comparative foraging ecology of a tropical seabird community of the Seychelles, western Indian Ocean. Mar Ecol Prog Ser 374:259-272

Cherel Y, Hobson KA, Bailleul F, Groscolas R (2005) Nutrition, physiology, and stable isotopes: new information from fasting and molting penguins. Ecology 86:2881-2888

Cherel Y, Le Corre M, Jaquemet S, Ménard F, Richard P, Weimerskirch H (2008) Resource partitioning within a tropical seabird community: new information from stable isotopes. Mar Ecol Prog Ser 266:281-291

Diamond AW (1983) Feeding overlap in some tropical and temperate seabird communities. Stud Avian Biol 8:24-46

Dunlop JN, Surman CA, Wooller RD (2001) The marine distribution of seabirds from Christmas Island, Indian Ocean. Emu 101:19-24

Ellegren H (1996) First gene on avian W chromosome (CHD) provides a tag for universal sexing of non-ratite birds. Proc Biol Sci 263:1635-1641

Forero MG, Hobson KA (2003) Using stable isotopes of nitrogen and carbon to study seabird ecology: applications in the Mediterranean seabird community. Sci Mar 67:23-32

Forero MG, Bortolotti GR, Hobson KA, Donazar JA, Bertelloti M (2004) High trophic overlap within the seabird community of Argentinean Patagonia: a multiscale approach. J Anim Ecol 73:789-801

Harrison CS, Hida TS, Seki MP (1983) Hawaiian seabirds feeding ecology. Wildlife Monogr 85:1-71

Hobson KA, Alisauskas RT, Clark RG (1993) Stable-nitrogen isotope enrichment in avian tissues due to fasting and nutritional stress: implications for isotopic analyses of diet. Condor 95:388-394

Hobson KA, Piatt JF, Pitocchelli J (1994) Using stable isotopes to determine seabird trophic relationships. J Anim Ecol 63:786-798

Hobson KA, Gilchrist G, Falk K (2002) Isotopic investigations of seabirds of the North Water Polynya: contrasting trophic relationships between the eastern and western sectors. Condor 104:1-11

Inger R, Bearhop S (2008) Applications of stable isotope analyses to avian ecology. Ibis 149:622-625

Karnovsky NJ, Hobson KJ, Iverson SJ (2012) From lavage to lipids: innovations and limitations in estimating diets of seabirds. Mar Ecol Prog Ser 451:263-284

Kojadinovic J, Ménard F, Bustamante P, Cosson RP, Le Corre M (2008) Trophic ecology of marine birds and pelagic fishes from Reunion Island as determined by stable isotope analysis. Mar Ecol Prog Ser 361:239-251 
Le Corre M, Cherel Y, Lagarde F, Lormée H, Jouventin P (2003) Seasonal and inter-annual variation in the feeding ecology of a tropical oceanic seabird, the re-tailed Tropicbird Phaethon rubricauda. Mar Ecol Prog Ser 255:289-301

Lewis S, Schreiber EA, Daunt F, Schenk GA, Wanless S, Hamer KC (2004) Flexible foraging patterns under different time constraints in tropical boobies. Anim Behav 68:1331-1337

Longhurst AR, Pauly D (1987) Ecology of tropical oceans. Academic Press, San Diego, CA

Masello JF, Mundry R, Poisbleau M, Demongin L, Voigt CC, Wikelski M, Quillfeldt P (2010) Diving seabirds share foraging space and time within and among species. Ecosphere 1:art19

Miller CB (2003) Biological oceanography. Blackwell, London, UK

Moreno R, Jover L, Velando A, Munilla I, Sanpera C (2011) Influence of trophic ecology and spatial variation on the isotopic fingerprints of seabirds. Mar Ecol Prog Ser 442:229-239

Moreno R, Jover L, Diez C, Sardà-Palomera F, Sanpera C (2013) Ten years after the prestige oil spill: seabird trophic ecology as indicator of long-term effects on the coastal marine ecosystem. PLoS ONE 8:e77360

Navarro J, González-Solís J, Viscor G (2007) Nutritional and feeding ecology in the Cory's shearwater (Calonectris diomedea) during breeding. Mar Ecol Prog Ser 351:261-271

Navarro J, Votier SC, Aguzzi J, Chiesa JJ, Forero MG, Phillips RA (2013) Ecological segregation in space, time and trophic niche of sympatric planktivorous petrels. PLOS ONE 8:e62897

Nelson JB (1972) The biology of seabirds of the Indian Ocean, Christmas Island. Mar Biol Ass India 14:643-662

Nelson JB (1978) The Sulidae. Oxford University Press, Oxford, UK

Phillips RA, Silk JRD, Croxall JP (2005) Foraging and provisioning strategies of the light-mantled sooty albatross at South Georgia: competition and co-existence with sympatric pelagic predators. Mar Ecol Prog Ser 285:259-270

Post DM (2002) Using stable isotopes to estimate trophic position: models, methods, and assumptions. Ecology 83:703-718

Ricklefs RE (1983) Some considerations on the reproductive energetics of pelagic seabirds. Stud Avian Biol 8:84-94

Shaffer SA, Costa DP, Weimerskirch H (2003) Foraging effort in relation to the constraints of reproduction in free ranging albatrosses. Funct Ecol 17:66-74

Sommerfeld J, Hennicke J (2010) Comparison of trip duration, activity pattern and diving behaviour between incubating and chick rearing red-tailed tropicbirds (Phaethon rubricauda). Emu 110:78-86

Spear LB, Ainley DG, Walker WA (2007) Foraging dynamics of seabirds in the eastern tropical pacific ocean. Stud Avian Biol 35:1-99

Stokes T (1988) A review of the birds of Christmas Island, Indian Ocean. Australian National Parks and Wildlife Service, Occasional paper No. 16. Australian National Parks and Wildlife Service, Canberra

Young HS, Shaffer SA, McCauley DJ, Foley DG, Dirzo R, Block BA (2010) Resource partitioning by species but not sex in sympatric boobies in the central Pacific Ocean. Mar Ecol Prog Ser 403:291-301

doi:10.1186/s40555-014-0027-

Cite this article as: Navarro et al:: Resource partitioning between incubating and chick-rearing brown boobies and red-tailed tropicbirds on Christmas Island. Zoological Studies 2014 53:27

\section{Submit your manuscript to a SpringerOpen ${ }^{\circ}$ journal and benefit from:}

- Convenient online submission

- Rigorous peer review

- Immediate publication on acceptance

- Open access: articles freely available online

- High visibility within the field

- Retaining the copyright to your article

Submit your next manuscript at $>$ springeropen.com 